\title{
PTSD, depression and anxiety among tsunami affected people in Thailand: A population-based longitudinal study
}

\author{
Benjaporn Panyayong ${ }^{1^{*}}$, Wachira Pengjantr ${ }^{2}$ \\ ${ }^{1}$ Somdet Chaopraya Institute of Psychiatry, Bangkok, Thailand; *Corresponding Author: bpanyayong@gmail.com \\ ${ }^{2}$ Department of Mental Health, Nonthaburi, Thailand
}

Received 6 September 2013; revised 6 October 2013; accepted 13 October 2013

Copyright (C) 2014 Benjaporn Panyayong, Wachira Pengjantr. This is an open access article distributed under the Creative Commons Attribution License, which permits unrestricted use, distribution, and reproduction in any medium, provided the original work is properly cited. In accordance of the Creative Commons Attribution License all Copyrights (C) 2014 are reserved for SCIRP and the owner of the intellectual property Benjaporn Panyayong, Wachira Pengjantr. All Copyright (C) 2014 are guarded by law and by SCIRP as a guardian.

\section{ABSTRACT}

Background: On December 26, 2004, Asian tsunami attacked the southern part of Thailand. The tsunami induced catastrophic consequences. There was no study of long-term mental health outcomes among adult survivors by natural disasters in Thailand. Objective: The purposes of the present study were to determine prevalence and longitudinal course of PTSD, depression, and anxiety among tsunami affecting Thai people, and to identify factors associated with PTSD, depression, and anxiety in this particular group. Material and Method: The present study was a population-based longitudinal study. The third mental health assessment was conducted among adult survivors older than 17 years at three years after tsunami. PTSD, depression and anxiety were assessed by using the Harvard Trauma Questionnaire (HTQ) and the Hopkins Checklist-25 (HSCL-25) respectively. Results: 550 of 693 affected people in Phang Nga province were enrolled in the follow-up survey at three years after tsunami. Prevalence of PTSD, anxiety, and depression among affected people decreased from 9.5\% (66/693), 33.6\% (233/693) and $25.7 \%(178 / 693)$, at two months after tsuna$\mathrm{mi}$, to $2.6 \%(13 / 503), 18.7 \%(94 / 503)$, and $14.1 \%$ $(71 / 503)$ at three years after tsunami respectively. Risk factors for mental health problems were post-traumatic life stress such as the loss of livelihood for PTSD, depression and anxiety, and pre-traumatic vulnerabilities such as sex (female), education, and previous mental illness for depression and anxiety. Conclusion: PTSD, depression and anxiety among tsunami affecting Thai people decreased over time. Pre-traumatic vulnerable factors and post-traumatic life stress were associated with PTSD, depression and anxiety. These results are acknowledgeable by two points: first, it is important to provide both mental health intervention and psychosocial intervention in rehabilitation phase for the affected people; second, duration of intervention should be at least three years after severely impacted disaster.

\section{KEYWORDS}

Mental Health; Prevalence; Disaster

\section{INTRODUCTION}

The Asian tsunami 2004 which struck 6 Andaman coastal provinces of Thailand on $26^{\text {th }}$ December, 2004, resulted in 5395 death and \$21 million dollars damage. As catastrophic consequences of tsunami on livelihoods, over 100,000 of local people whose livelihood depended on the tourism industry suddenly lost their jobs. Over 400 fishing communities were affected by tsunami. Many who were already poor and struggling to earn their living were particularly affected by the disaster. Phang Nga province was the most seriously affected area [1].

Psychological consequences of disaster were acute stress disorder, anxiety, depression, posttraumatic stress disorder (PTSD), suicide, substance use disorder, etc. Prevalence of PTSD from natural disaster was in the range from $2.6 \%$ to $57.3 \%$ [2-7] depended on type and 
severity of disasters, study design, assessment tools, studied population and time-frame of data collection. From the study of van Griensven, the same population in Phang Nga province of the present study, the prevalence of PTSD, depression, and anxiety were found to be $9.5 \%$ (11.9\% for displaced people, 6.8\% for non-displaced), $25.6 \%$ (30.2\% for displaced people, $20.5 \%$ for non-displaced) and 33.6\% (36.9\% for displaced people, 29.8\% for non-displaced) in the first survey at 2 months posttsunami respectively [8]. The prevalence of PTSD, depression, and anxiety was 4.8\% (7.0\% for displaced people, $2.3 \%$ for non-displaced), $15.6 \%$ (16.7\% for displaced people, $14.3 \%$ for non-displaced) and $25.4 \%$ (24.8\% for displaced people, $25.9 \%$ for non-displaced) in the second survey at 9 months after tsunami respectively [8]. Prevalence of anxiety and depression was still high at 9 months after tsunami.

Factors significantly associated with mental problems were severity of exposure, oneself or family members injured, lost home or properties, family members died or missing during tsunami, lost livelihood, and previous vulnerabilities (e.g. age, sex (female), education and etc.) at 2 months after tsunami [8].

Mental health problems in natural disaster-affected individuals decreased over time [7-10]. Patterns of declination of symptoms and prevalence of psychiatric disorders, mentioned by Pietrzak et al., were as follows: a simple linear decline, an initial decline followed by stabilization, and a quadratic pattern of change [9].

The associated factors for mental health outcomes after disaster were divided into type and severity of trauma, previous vulnerability (e.g. gender, age at trauma, SES, education, previous psychological disorder), post-trauma life stress, and post-trauma social support [11].

Few population-based longitudinal studies were conducted in large-scale population and mostly not extended beyond one follow-up [9]. There were follow-up studies among tsunami-affected children in Thailand in the same schools, but there were no population-based studies [12]. The present study was only one population-based longitudinal study of mental health problems among affected adults after natural disaster in Thailand. The present study advanced the disaster mental health literatures in two important points. First, it was one of very few longitudinal studies conducting more than one follow-up assessment after natural disaster. Second, it included an assessment of factors for mental health outcomes at three years after disaster.

Objective of the present study was to determine prevalence and longitudinal course of PTSD, depression and anxiety among tsunami-affected people in Phang Nga and to identify risk factors associated with PTSD, depression and anxiety in these groups.

\section{MATERIAL AND METHODS}

The present study was a population-based longitudinal study of prevalence of PTSD, depression and anxiety among affected people by Asian tsunami 2004. The first and the second mental health assessments were conducted among adults and children in the affected provinces at 2 and 9 months post-tsunami in February and September 2005 by the collaborative team of the Department of Mental Health (DMH) of the Royal Thai Government and Thailand Ministry of Public HealthUS Centers for Disease Control and Prevention Collaboration (TUC) that explained elsewhere [8,13]. The third survey was conducted by the DMH. In the first survey, the sample aged over 15 years were recruited as followed; 693 were affected people in Phang Nga (371 were displaced persons and 322 were non displaced persons), and 368 were affected people in Krabi and Phuket. The sample size was calculated by the estimated prevalence of PTSD 15\% in displaced group and $12.5 \%$ in non displaced group with $2 \%$ design effect. The sample was selected by multistage cluster household sampling from 10 out of 16 shelters, 16 villages in Phang Nga and 16 villages in Phuket and Krabi which explained by van Griensven's study [8]. All of affected people in Phang Nga province in the first survey were selected as sample of the present study.

\subsection{Instruments and Data Collection}

The questionnaires composed of social demographic data, tsunami-specific traumatic events, and health assessment tools. The Medical Outcomes Study-36 ShortForm Health Survey (SF-36) [14,15], the Harvard Trauma Questionnaire(HTQ) [16], and the Hopkins Checklist-25 (HSCL-25) [17] were used to determine health conditions. The HTQ was used to assess tsunami-traumatic events (part one, 13 questions) and to assess PTSD (part two, 16 questions). A score of 3 or 4 was on at least 1 of 4 re-experiencing symptoms, at least 3 of 7 avoidance and numbing symptoms, and at least 2 of 5 arousal symptoms were used to identify PTSD, that based on DSM-IV criteria [16]. The HSCL-25 was used to detect symptoms of anxiety and depression. It comprises a 10item subscale for anxiety and a 15-item for depression. Mean cumulative symptom scores higher than 1.75 indicated the presence of anxiety and depression [17].

The study proposal was submitted, reviewed, and officially authorized by the ethic committee of Department of Mental Health, Ministry of Public Health before conducting the survey (reference number 21/2551). All participants of this study were asked for verbal informed consent. Data collection consisted of face-to-face interviews carried out in a temporary housing structure and a home. People in need of mental health support were referred to mental health services available both in tempo- 
rary shelters and in community areas. The third survey was conducted from February 11th to 18th, 2008 (3 years after tsunami) by the DMH team. People whose houses were destroyed or damaged and lived in the temporary shelters were defined as displaced people.

\subsection{Data Analysis}

The prevalence of PTSD, depression, anxiety and their risk factors were calculated and analyzed using SPSS version 14.0. We used descriptive statistics to sum- marize the demographic data and traumatic experiences. Correlation between the outcome variables of PTSD, depression, anxiety, and the independent variables was assessed by using multivariate analysis. A p-value of 0.05 was considered as significant. Odds ratios (OR) with 95\% confidence intervals (95\% CI) were calculated. Factors for PTSD, depression and anxiety included sex, age, marital status, education, tsunami-specific traumatic events (e.g. lost spouse, lost children, oneself injured, etc.), and social supports.

\section{RESULTS}

\subsection{Demographic Characteristics and Traumatic Experiences of Disaster}

In the third survey, 503 of 693 affected people from the first survey were followed up (participation rate $72.6 \%$ ). Of the 503 affected people, $62.4 \%$ were female, $77.1 \%$ were Buddhist, $72.5 \%$ graduated primary school or below, $75.7 \%$ were married/living together. Their mean age was $45.4 \pm 15.5$ years (range from 17 years to 89 years). Most of the affected people felt that it was difficult to resume regular income. Even through, 62.7\% of the affected people got support at least 2 items of social supports (financial aid, housing, employment, and material/equipments) (Table 1 ). Table 1 showed that the experiences of tsunami-traumatic events were lost properties $69.2 \%$, lost home $54.5 \%$, lost children $7.2 \%$, death of spouses $4.2 \%$, oneself or family members injured $51.7 \%$ and one-fourth lost livelihood.

\subsection{General Health and Somatic Symptoms}

For general health problems, the affected people got headache $57.7 \%$, sleep trouble $55.1 \%$, stomach pain $31.8 \%$, and drink alcohol more than 3 glasses/day 2.8\% (Table 2). Our data found that the affected people who thought that life was not worth living were $4.6 \%$. Perception of general health, bodily pain, social functioning and emotional-role functioning were displayed in Table 2.

\subsection{Prevalence of PTSD, Depression, and Anxiety at 3 Years Post-Tsunami}

The prevalence of PTSD, depression and anxiety were
Table 1. Demographic characteristics and tsunami experiences $(n=503)$.

\begin{tabular}{ll}
\hline Characteristics/experiences & $\mathrm{n} \%$ \\
\hline Sex & \\
Female & $314(62.4)$ \\
Male & $189(37.6)$ \\
Marital status & \\
Married/living together & $381(75.7)$ \\
Unmarried/separated/divorce & $122(24.3)$ \\
Religion & \\
Buddhist & $388(77.1)$ \\
Muslim & $106(21.1)$ \\
Others & $9(1.8)$ \\
Education & $315(62.7)$ \\
Primary school or lower & $126(25.0)$ \\
Secondary level/higher & $416(82.7)$ \\
Tsunami experiences & $365(72.5)$ \\
Lost their children & $138(27.5)$ \\
Death of spouses & $274(54.5)$ \\
Family members died or missing during tsunami & $168(33.4)$ \\
Known persons died or missing during tsunami & $450(89.5)$ \\
Oneself or family member injured & $260(51.7)$ \\
Lost properties & $36(7.2)$ \\
Lost home & $21(4.2)$ \\
\hline Multiple loss at least 4 items & \\
\hline & \\
\hline
\end{tabular}

$2.6 \%$ (3.2\% for female and 1.6\% for male), $14.1 \%$ (16.9\% for female and $9.5 \%$ for male), and $18.7 \%$ (22.6\% for female and $12.2 \%$ for male) respectively. The prevalence of depression and anxiety were significantly higher in female than male. The co-morbidity of depression and anxiety among PTSD were 92.3\% (12/13) and 84.6\% (11/13) respectively. Of the individuals with depression, $16.9 \%(12 / 71)$ had symptoms of PTSD. Suicidal ideation among survivors with PTSD was 15.4\% (2/13) and among depressive persons was 18.3\% (13/71). 


\subsection{Factors Associated with PTSD, Depression and Anxiety in Multivariate Analysis}

The factors suggested by bivariate analysis that associated with PTSD, depression and anxiety were entered into a binary logistic analysis model.

Table 2. Somatic symptoms, suicide, and general health $(\mathrm{n}=$ 503).

\begin{tabular}{lll}
\hline Symptoms & $\mathrm{n} \%$ \\
\hline Headache & $290(57.7)$ \\
Sleep problems & $277(55.1)$ \\
Stomach pain & $160(31.8)$ & \\
Previous mental illness & $18(3.6)$ & \\
Use of illicit drugs & $12(2.4)$ & \\
Drink alcohol $\geq 3$ glasses/day & $14(2.8)$ & \\
Suicide idea (quite a bit/most of the time $) 23(4.6)$ & $(4(0.8))$ \\
$\begin{array}{l}\text { Family members had suicide ideation } \\
\text { (attempted suicide) }\end{array}$ & $22(4.4)$ & $(4(0.8))$ \\
& Female & Male \\
& Mean \pm SD & Mean \pm SD \\
Eomotion-role function & $66.7( \pm 23.1)$ & $66.3( \pm 26.4)$ \\
\hline $\begin{array}{l}\text { General health perception } \\
\text { Social functions }\end{array}$ & $74.9( \pm 26.6)$ & $74.6( \pm 25.5)$ \\
& $79.6( \pm 24.6)$ & $79.6( \pm 26.5)$ \\
& $85.4( \pm 19.0)$ \\
\hline
\end{tabular}

In the third survey, affected people who lost their livelihood got higher rate of PTSD than those who didn't have such factors 10.1 times. For depression, women who had previous mental illness and lost their livelihood got higher prevalence rate of depression when compared to male and those who didn't have such factors 2.0, 3.2, 5.7 times respectively. The affected women who graduated secondary school or higher and those who had previous mental illness and lost their livelihood got higher prevalence of anxiety when compared to male with lower education and those who didn't have such factors 2.0, 2.2, 3.0 and 2.6 times respectively (Table 3 ).

\section{DISCUSSION}

The prevalence of PTSD among the affected people decreased by $49.5 \%$, from $9.5 \%$ (66/693) to $4.8 \%$ (25/ 520 ), in the second survey and up to $72.6 \%$ to $2.6 \%$ $(13 / 503)$ in the third survey. The prevalence of depression among affected people decreased by $39.1 \%$, from $25.6 \%(178 / 693)$ to $15.6 \%(81 / 520)$, in the second survey and slightly decreased to $14.1 \%(71 / 503)$ in the third survey. The prevalence of anxiety among affected people decreased by $24.4 \%$, from $33.6 \%$ (233/693) to $25.4 \%$ $(132 / 520)$, in the second survey and up to $44.3 \%$ to $18.7 \%(94 / 503)$ in the third survey. The present study found that, in the survivors of tsunami, the symptoms of anxiety and depression were more common than PTSD which were similar to finding from the other study [18]. Finding of decrease in the prevalence rate of PTSD, anxiety and depression over time was consisting with finding from other studies $[7-10,12,19,20]$. The prevalence of

Table 3. Multivariate analysis for factors associated with PTSD, depression, and anxiety among affected people in the $3^{\text {rd }}$ survey (n $=$ 503).

\begin{tabular}{|c|c|c|c|c|c|c|}
\hline & PTSD OR (95\% CI) & $p$ value & Depression OR (95\% CI) & p value & Anxiety OR (95\% CI) & $p$ value \\
\hline \multicolumn{7}{|l|}{ Sex } \\
\hline Female & N/A & & $2.04(1.13-3.70)$ & 0.023 & $2.06(1.22-3.49)$ & 0.007 \\
\hline Male & & & 1 & & 1 & \\
\hline \multicolumn{7}{|l|}{ Education } \\
\hline Secondary level/higher & N/A & & N/A & & $2.23(1.18-4.22)$ & 0.001 \\
\hline Primary school/lower & & & & & 1 & \\
\hline \multicolumn{7}{|l|}{ Previous mental illness } \\
\hline Yes & N/A & & $3.22(1.16-8.93)$ & 0.025 & $3.04(1.08-8.56)$ & 0.035 \\
\hline No & & & 1 & & 1 & \\
\hline \multicolumn{7}{|l|}{ Lost livelihood } \\
\hline Yes & $10.06(2.72-37.13)$ & 0.001 & $5.71(3.35-9.72)$ & 0.000 & $2.61(1.61-4.25)$ & 0.000 \\
\hline No & 1 & & 1 & & 1 & \\
\hline
\end{tabular}


PTSD and anxiety showed a continuously linear decline. Declination of prevalence rate of PTSD might be explained by natural recovery and psychosocial supports. According to most of the affected people living close to the Andaman Sea and they were natural exposed to the sea as a part of naturally recovery. Moreover, the affected individuals with mental illness received interventions from mobile mental health team in communities and home visited from GO, NGOs in Phang Nga for at least 3 years since the tsunami [21].

The prevalence of depression initially decreased nearly by half in the second survey and was relatively stable between the $2^{\text {nd }}$ and the $3^{\text {rd }}$ survey (15.1\% and $14.1 \%$ ). The high prevalence rate of anxiety and depression (25.1\% and $15.1 \%)$ at 9 months; and (18.7\% and $14.1 \%)$ at three years post-tsunami might be explained by other related stressors (e.g. lost of loved one, oneself injured, etc.). Approximately one-fourth of those who experienced tsunami had multiple losses at least 4 of 13 lost items. These stressors were significantly associated with disaster-exposed individuals with anxiety and mood disorders [22,23] which associated with the slow pace of practical recovery efforts (housing, utilities and jobs) [24]. Moreover, most of the affected people found it difficult to gain regular income and one-fourth of them still lost their livelihood at 3 years post-tsunami.

Even though, medical outcomes of the survivors such as general health perception, bodily pain, emotional-role functioning and social functioning were the same as general population [15]. Meanwhile, the affected people got psychosocial supports from Government organization, NGOs, the UN and private sectors. Two thirds of them received supports at least 2 of 4 items such as financial aid, housing, employment, material or equipments. The affected people needed both mental health support and psychsocial support especially careers and incomes. Our finding suggested that mental health team should be more concerned about the psychosocial aspects and appropriated interventions.

Our data showed that women got depression and anxiety more than men. The current finding was consistent with finding of others such as Ditlevsen [25]. Anyway, there were mixed finding in many studied that mentioned in meta-analysis of risk factors for PTSD by Brewin [11].

The associated factors for depression were previous vulnerabilities (such as sex (female), and previous mental illness) and post-traumatic stressors (lost livelihood). Factors that associated with anxiety were previous vulnerabilities (such as; sex (female), higher education (secondary level or higher), and previous mental illness) and post-traumatic stressors (lost livelihood). The persons who had previous vulnerability (such as sex (female), previous mental illness) were susceptible to mental illness post-natural disaster. The present study showed that all of mental health problems (PTSD, depression and anxiety) were significantly associated with the loss of livelihood which was similar to the finding in the first survey [12]. Restoration of persons' livelihood among these people who were affected by natural disasters is most importance.

The present study found that the prevalence of suicidal ideation among the survivors was $4.6 \%$ and were relatively high among individuals with PTSD and depression (15.4\% VS $18.3 \%)$. The results were similar to the finding of others which the past month suicidal ideation prevalence was $4.2 \%$ at 18 months after Hurricane Ike [9] but higher than the study after Hurricane Katrina [26]. Five percent of family members also had suicidal ideation. Causes of suicidal ideation might be from multiple losses and post-tsunami life stresses such as the difficulty to resume regular income and lost livelihood.

\section{LIMITATION}

The authors found that there were two limitations. First, the instruments were not clinically validated in the Thai culture. Second, the present study could only recruit approximately $73 \%$, this might be explained by migration out of the affected area and relocation that usually happen after large scale disasters. The present study didn't recruit the affected people in Krabi and Phuket which were the less seriously affected areas with low prevalence rate of mental health problems from the first survey [8]. Future research needs to examine appropriate intervention after natural disaster in the country.

\section{CONCLUSION}

The prevalence of PTSD, depression, and anxiety decreased over time. Prevalence of PTSD and anxiety was continuously linearly declined from 2 months to 3 years after tsunami, but the prevalence of depression initially rapidly decreased and was relatively stable. Sex (female), previous mental illness and loss of livelihood were strongly associated with depression, and anxiety in longterm effects. Only loss of livelihood was associated with PTSD. These results give guidance that the affected people would need long-term intervention—both mental health intervention and psychosocial intervention.

\section{ACKNOWLEDGEMENTS}

The authors thank the personnel of the Department of Mental Health, Phang Nga provincial and District Offices for their help in conducting the study; the Thailand Ministry of Public Health-US Centers for Disease Control and Prevention (TUC).

\section{REFERENCES}

[1] World Bank (2005) Tsunami Thailand-one-year later: National response and contribution of international partners. 
World Bank Report.

[2] Amstadter, A.B., Acierno, R., Richardson, L.K., Kilpatrick, D.G., Gros, D.F., Gaboury, M.T., et al. (2009) Posttyphoon prevalence of posttraumatic stress disorder, major depressive disorder, panic disorder, and generalized anxiety disorder in a Vietnamese sample. Journal of Traumatic Stress, 22, 180-188.

http://dx.doi.org/10.1002/jts.20404

[3] Acierno, R., Ruggiero, K.J., Galea, S., Resnick, H.S., Koenen, K., Roitzsch, J., de Arellano, M., Boyle, J. and Kilpatrick, D.G. (2007) Psychological sequelae resulting from the 2004 Florida hurricanes: Implications for postdisaster intervention. American Journal of Public Health, 97, S103-S108. http://dx.doi.org/10.2105/AJPH.2006.087007

[4] Wang, L., Zhang, Y., Wang, W., Shi, Z., Shen, J., Li, M. and Xin, Y. (2009) Symptoms of posttraumatic stress disorder among adult survivors three months after the Sichuan earthquake in China. Journal of Traumatic Stress, 22, 444-450. http://dx.doi.org/10.1002/jts.20439

[5] Huang, P., Tan, H., Liu, A., Feng, S. and Chen, M. (2010) Prediction of posttraumatic stress disorder among adults in flood district. BMC Public Health, 10, 207. http://www.biomedcentral.com/1471-2458/10/207 http://dx.doi.org/10.1186/1471-2458-10-207

[6] Thavichachart, N., Tangwongchai, S., Worakul, P., Kanchanatawan, B., Suppapitiporn, S., Sukoltapirom, Pattalung, A., et al. (2009) Posttraumatic mental health establishment of the tsunami survivors in Thailand. Clinical Practice \& Epidemiology in Mental Health, 5, 11. http://dx.doi.org/10.1186/1745-0179-5-11

[7] Piyasil, V., Ketuman, P., Prubrukarn, R., Ularntinon, S., Sithiraksa, N., Pithayaratsatien, N., et al. (2008) Posttraumatic stress disorder in children after the tsunami disaster in Thailand: A 3 years follow up. ASEAN Journal of Psychiatry, 9, 99-103.

[8] van Griensven, F., Chakkraband, M.L.S., Thienkrua, W., Pengjuntr, W., Cardozo, B.L., Tantipiwatanaskul, P., et al. (2006) Rapid assessment of post-tsunami mental health problems among adults in southern Thailand. JAMA, 296, 537-548. http://dx.doi.org/10.1001/jama.296.5.537

[9] Pietrzak, R.H., Tracy, M., Galea, S., Kilpatrick, D.G., Ruggiero, K.J., Hamblen, J.L., Southwick, S.M., et al. (2012) Resilience in the face of disaster: Prevalence and longitudinal course of mental disorders following Hurricane Ike. Plos ONE, 7, e38964. http://dx.doi.org/10.1371/journal.pone.0038964

[10] Neria, Y., Nandi, A. and Galea, S. (2008) Post-traumatic stress disorder following disasters: A systemic review. Psychological Medicine, 38, 467-480. http://dx.doi.org/10.1017/S0033291707001353

[11] Brewin, C.R., Andrew, B.A. and Valentine, J.D. (2000) Meta-analysis of risk factors for posttraumatic stress disorder in trauma-exposed adults. Journal of Consulting \& Clinical Psychology, 68, 748-766. http://dx.doi.org/10.1037/0022-006X.68.5.748

[12] Piyasil, V., Ketumarn, P., Prubrukarn, R., Ularntinon, S., Sitdhiraksa, N., Pithayaratsathien, N., et al. (2011) Posttraumatic stress disorder in children after the tsunami disaster in Thailand: A 5-years follow-up. Journal of the Medical Association of Thailand, 94, S138-S144.

[13] Thienkrua, W., Lopes Cardozo, B., Chakkraband, S., Guadamaz, T.E., Pengjuntr, W., Tantipiwatanaskul, T., et al. (2006) Tsunami-related post-traumatic stress disorder and depression among children in southern Thailand. JAMA, 296, 549-559. http://dx.doi.org/10.1001/jama.296.5.549

[14] McHorney, C.A., Ware, J.E. and Raczek, A.E. (1993) The MOS 36-item short-form health survey (SF-36): II psychometric and clinical tests of validity in measuring physical and mental health constructs. Medical Care, 31, 247-263.

http://dx.doi.org/10.1097/00005650-199303000-00006

[15] Kongsakon, R., Silpakit, C. and Udomsubpayakul, U. (2007) Thai normative data for the SF-36 health survey: Bangkok metropolitan. ASEAN Journal of Psychiatry, 8, 131-137.

[16] Mollica, R.F., Caspi-Yavin, Bollini, P., Truong, T., Tor, S. and Lavelle, J. (1992) The Havard trauma questionnaire: Validity a cross-cultural instrument for measuring torture, trauma, and posttraumatic stress disorder in Indochinese refugees. The Journal of Nervous and Mental Disease, 180, 111-116. http://dx.doi.org/10.1097/00005053-199202000-00008

[17] Mollica, R.F., Wyshak, G., de Marneffe, D., Khuon, F. and Lavelle, J. (1987) Indochinese versions of the Hopkins symptom checklist-25: A screening instrument for the psychiatric care of refugees. Journal of the American, 144, 497-500.

[18] Kar, N., Jagadisha, Sharma, P., Murali, N. and Mehrotra, S. (2004) Mental health consequences of the trauma of super-cyclone 1999 in Orissa. Indian Journal of Psychiatry, 46, 228-237.

[19] Lima, B.R., Pai, S., Toledo, V., Caris, U., Haro, J., Lozano, J.C., et al. (1993) Emotional distress in disaster victims: A follow-up study. Journal of Nervous and Mental Disease, 65, 311-317.

[20] North, C.S., Kawasaki, A., Spitznagel, E.L. and Hong, B.A. (2004) The course of PTSD, major depression, substance abuse, and somatization after a natural disaster. Journal of Nervous and Mental Disease, 92, 823-829. http://dx.doi.org/10.1097/01.nmd.0000146911.52616.22

[21] Chakrabhand, S., Panyayong, B. and Sirivech, P. (2006) Mental health and psychosocial support after the tsunami in Thailand. International Review of Psychiatry, 18, 599605. http://dx.doi.org/10.1080/09540260601038274

[22] Kessler, R.C., McLaughlin, K.A., Koenen, K.C., Petukhova, M., Hill, E.D. and The WHO World Mental Health Survey Consortium (2012) The importance of secondary trauma exposure for post-disaster mental disorder. Epidemiology and Psychiatric Sciences, 21, 35-45. http://dx.doi.org/10.1017/S2045796011000758

[23] Tracy, M., Norris, F.H. and Galea, S. (2011) Differences in the determinants of posttraumatic stress disorder and depression after a mass trauma event. Depress Anxiety, 28, 666-675. http://dx.doi.org/10.1002/da.20838

[24] Galea, S., Brewin, C.R., Gruber, M., Jones, R.T., King, D.W., King, L.A., et al. (2007) Exposure to hurricane- 
related stressors and mental illness after Hurricane Katrina. Archives of General Psychiatry, 64, 1427-1434.

http://dx.doi.org/10.1001/archpsyc.64.12.1427

[25] Ditlevsen, D.N. and Eiklit, A. (2010) The combined effect of gender and age on posttraumatic stress disorder: Do men and women show differences in the life span distribution of the disorder? Annals of General Psychiatry, 21,
32-39. http://dx.doi.org/10.1186/1744-859X-9-32

[26] Kessler, R.C., Galea, S., Jones, R.T., Parker, H.A. and Hurricane Katrina Community Advisory Group (2006) Mental illness and suicidality after Hurricane Katrina. Bulletin of the World Health Organization, 84, 930-939. http://dx.doi.org/10.2471/BLT.06.033019 